\title{
Rationalizing Criminal Behaviour: The Influence of Criminal Sentiments on Sociomoral Development in Violent Offenders and Nonoffenders
}

\author{
Sally F. Stevenson \\ Guy Hall \\ J. M. Innes
}

\begin{abstract}
Cognitive developmental theory suggests that mature-level sociomoral reasoning (Stages 3 and 4) can provide a protective factor, or buffer, against antisocial and violent criminal behavior. This study explored whether the influence of internalised criminal sentiments could undermine this buffer. The sample was high-risk men and women offenders $(\mathrm{n}=99)$ convicted of serious violent index offences, and men and women nonoffender university students $(\mathrm{n}=$ 101). Moral reasoning was measured using the Sociomoral Reflection Measure-Short Form, whereas criminal sentiments were assessed using the Criminal Sentiments Scale. Based on moral reasoning development level the sample was classified into groups: mature- or immaturelevel moral reasoners. The results suggested that mature-level sociomoral development might not protect a person from identifying with criminal others, and that law violation could be rationalized regardless of sociomoral level. Gender differences were neither expected nor found. The applied implications of the findings are considered.
\end{abstract}

Keywords: criminal attitudes; sentiments; violent offenders; moral development; neutralizations

High-risk violent offenders make up a small proportion of the offending population but cause the greatest concern to the community. They commit most of the reported violent offences, and the offences they commit cause the greatest harm (refer to Farrington, 1997). Being high-risk offenders, they should be the target of intervention that should focus on criminogenic needs (Andrews \& Bonta, 1998). Two criminogenic needs that have been suggested to underpin violent behaviour are sociomoral-reasoning immaturity (Goldstein, Glick, \& Gibbs, 1998) and criminal thinking in the form of pro-offending sentiments (Simourd, 1996; Walters, 1990). These two variables have been central in an ongoing debate concerning whether it was how offenders thought (moral reasoning) versus what

NOTE: Correspondence concerning this article should be addressed to Sally F. Stevenson, School of Psychology, Murdoch University, South Street, Murdoch, Western Australia, 6150; e-mail: sstevens@ central.murdoch.edu.au

International Journal of Offender Therapy and Comparative Criminology, 48(2), $2004 \quad$ 161-174 DOI: $10.1177 / 0306624 X 03258483$

(C) 2004 Sage Publications 
offenders thought (criminal sentiments) that represents risk factors for violent recidivism.

Moral development theorists argued that what differentiated aggressive offenders from nonoffenders was the way offenders reasoned through their actions and how their social worldview was constructed vis-à-vis their interpersonal relationships and adherence to social norms (Goldstein et al., 1998). The emphasis of this position was on the structural level of moral reasoning, wherein developmental delay at the immature level provided a pragmatic worldview with little understanding of the perspectives of others. In contrast, social psychological theorists argued that an important risk factor was the presence of pro-offending sentiments with an absence of prosocial sentiments (cognitive content). The argument was that in situations in which stress levels were high, and/or temptations present, offending behaviour was more likely if a person had pro-offending sentiments, could rationalize their acts, and believed others would support them (Andrews \& Bonta, 1998).

These positions have been viewed as unrelated, possibly due to the insistence of Kohlberg (see Jennings, Kilkenny, \& Kohlberg, 1983) that reasoning and attitudes were independent. However, De Vries and Walker (1986) argued that as cognitive content represented subjective attitudes and with structure conceptualised as the reasoning underlying content, it made little sense to assume there was no relationship between structure and content in decision making. Andrews \& Bonta (1998) argued that relating criminal sentiments to aspects of development would enhance our knowledge. Exploring how criminal sentiments interact at different levels of sociomoral reasoning for violent adult offenders has not been addressed: This was the aim of this study.

\section{SOCIOMORAL DEVELOPMENTAL DELAY AND CRIMINAL AND/OR VIOLENT BEHAVIOR}

Jennings et al. (1983) suggested that developmental fixation at the immature stages of reasoning (Kohlberg's Stages 1 to 2/3), although not directly causal, was associated with violent and criminal behavior. This level was related to antisocial behavior, because social norms would only be upheld when the consequences maximised self-interest and minimised detrimental effects. This conditional upholding was based on a perception that the world was "dog eat dog" and where others would use you if you let them get away with it. Therefore, looking out for number one would be a reasonable basis for norm violation (Jennings et al., 1983). The converse of the delay hypothesis was that mature-level reasoning (Stages 3 to 4 ) could act as a buffer against antisocial influences. The buffer represented the characteristics of mature-level reasoning, empathic concern for others, and the ability to understand the implications of your actions for others (Jennings et al., 1983).

Most of the work investigating sociomoral delay has concentrated on young offenders. This research found that the majority of male and female young offend- 
ers used immature reasoning as the basis for moral decision making, whereas nonoffenders used the mature level (refer to Gibbs, Basinger, \& Fuller, 1992). Only a few studies have investigated the delay hypothesis with adult offenders. Two studies (both with samples of $n=20$ ) supported the delay hypothesis, with men offenders demonstrating immature-level reasoning (Thornton \& Reid, 1982; Valliant, Gauthier, Pottier, \& Kosmyna, 2000). In contrast, a study by Griffore and Samuels (1978) found no difference between 30 male maximum-security inmates and general population norms, with most offenders using mature reasoning. A study by Stevenson, Hall, and Innes (in press) compared 99 men and women violent offenders with 101 men and women nonoffenders. These researchers found that although offenders' reasoning was lower than the nonoffenders, the majority of offenders demonstrated mature reasoning (Stage 3 or above).

\section{CRIMINAL SENTIMENTS AND CRIMINAL AND/OR VIOLENT BEHAVIOR}

Criminal sentiments are defined as a set of attitudes and beliefs representing proximal personal and interpersonal support for criminal behavior. These sentiments have been found to represent three constructs: attitudes toward the justice system, tolerance for law violation (neutralisations), and identification with criminal others (Andrews \& Wormith, 1984).

Research investigating criminal sentiments has found a series of relationships in which negative attitudes toward the justice system have related to a higher willingness to rationalize criminal behavior, and a higher identification with criminal peers, and with offenders endorsing higher procriminal sentiments than nonoffenders (Simourd, 1996; Stevenson et al., in press). Furthermore, meta-analytical studies found that procriminal sentiments predicted a criminal past and future for adult men, explaining $40 \%$ of the variance in 3-year recidivism (Andrews \& Bonta, 1998), as well as the highest factor for recidivism (Gendreau, Little, \& Goggin, 1996) and maintenance of a criminal lifestyle (Walters, 1990, 2002).

The findings suggest a relationship existed between endorsement of procriminal sentiments and recidivism; however, what has been argued is whether endorsement has an underlying psychological purpose. Sykes and Matza (1957) proposed that criminal sentiments were definitions that offenders used to neutralise offending behaviour. Sykes and Matza hypothesised that neutralisations would operate before an act. However, clinical observations from justice personnel implied that neutralisations could be used prior, during, or after criminal involvement (Andrews \& Bonta, 1998). Five neutralisations were proposed: denial of responsibility, denial of harm, denial of the victim, condemnation of the condemners, and appeals to higher loyalties. Akers (1985) considered that most offenders were neither committed to law-abiding nor offending behaviour. Therefore, social values would not be rejected outright, but knowing how to rationalize offending behavior provided choice in whether to engage in crime or to deal with guilt during or after. In essence, neutralisations provided reasoning that the delib- 
erate harming of others was not right, but under certain circumstances certain acts were necessary and/or justifiable.

\section{LINKING ENDORSEMENT OF CRIMINAL SENTIMENTS TO SOCIOMORAL DEVELOPMENT}

In principle, the worldview provided at the mature level is theoretically inconsistent with violent acts because the consequences for others are severe. However, the results of Griffore and Samuels (1978) and Stevenson et al. (in press) indicated that the majority of adult offenders demonstrated mature-level sociomoral reasoning. Therefore, if mature reasoning can buffer against violent behavior, it was somehow undermined. This study proposes that one of the mechanisms by which the buffer is undermined is the internalisation of criminal sentiments. Thus, "what you think could have a powerful influence on how you think." This proposition is based on the following rationale.

First, Bandura (1977) argued that the orientation of mature-level reasoners was to show honour and to be loyal to peers, which could under some circumstances undermine adherence to prosocial norms. Although Bandura suggested this related to adolescent peer affiliation, there is no reason why this would not generalise to adult offenders.

Secondly, immature sociomoral reasoning was linked to criminal and/or violent behaviour because the decision to uphold or violate social norms (such as assault, theft) would only be upheld where the consequences maximised selfinterest and minimised detrimental effects. Therefore, it seems intuitive that such a worldview would be consistent with high internalisation of criminal sentiments, for example "The police are on the take, everybody breaks the law, so why shouldn't I?" In contrast, the worldview provided by the mature level is underpinned by the ability to understand the implications of your actions for others. As perspective taking is a necessary condition for progression to the mature level, Jennings et al. (1983) suggested this would translate into a more consistent upholding of social norms. However, practitioners have noted that criminal sentiments appear to be enduring and highly resistant to change (Simourd, 1996). If criminal sentiments are integrated into an individual's belief system, then sociomoral progression may simply accommodate them.

This study had two aims: first, to explore whether endorsement of criminal sentiments interacted differently at the immature and mature level of sociomoral development. The following patterns of endorsement of criminal sentiments were predicted: immature-level violent offenders would endorse higher criminal sentiments than mature-level violent offenders, followed by mature-level nonoffenders. Second, most research on offenders has concentrated on males, probably due to the disproportionately high levels of males in the offending population. Unfortunately, this has resulted in a limited understanding of female offenders. To avoid bias, and in recognition of the increasing level of female violence (Australian Institute of Criminology, 2001), women were included in this study. However, 
consistent with previous research (Alarid, Burton, \& Cullen, 2000), gender differences were not predicted.

\section{METHOD}

\section{PARTICIPANTS}

Participants were 200 adult men and women Australian citizens or permanent residents recruited from two naturally occurring populations. Participation was voluntary, with no rewards provided. All participants were debriefed after the data were collected and were assured of the confidentiality of their responses. Consent was freely obtained and was in accordance with the Australian Psychological Society's ethical guidelines.

Offender participants were incarcerated at four West Australian metropolitan prisons. ${ }^{1}$ The men and women offenders had all been convicted of serious, nonsexual, violent index offences (homicide, armed robbery, aggravated assault). Sentence length ranged from 3 years to life. The offenders had all served 6 months of their sentences, and none had participated in moral reasoning or criminal sentiments intervention. One hundred and thirteen offenders were invited to participate; 99 consented. Forty-one were women, mean age of $30(S D=9.48)$, and 58 were men, mean age of $32(S D=8.78)$. The offenders were assessed as being at high risk for violent reoffending. This assessment was based on the Level of Service Need Inventory (LOSNI), which targets six recidivism predictors: level of drug use, level of alcohol use, age at first offence, history of generalised offending, highest degree of personal injury occurring in index, and past violent offences. The LOSNI has a predictive accuracy for violent recidivism of between .72 to .76 for this population (Ward \& Dockerill, 1999).

The nonoffenders were first- and second-year Murdoch University undergraduates. Of the 331 questionnaires distributed, 101 scorable forms were returned. Of these, 54 were women, mean age of $26(S D=8.84)$, and 47 were men, mean age of $28(S D=9.21)$.

\section{MEASURES}

Sociomoral reasoning. The Sociomoral Reflection Measure-Short Form (SRM-SF) (Gibbs et al., 1992) is a paper-and-pencil production measure designed to assess stage of sociomoral reasoning. Eleven social values are assessed including contract, affiliation, life, property, law, and legal justice. Participants are asked to indicate whether they think each value is important or not and secondly, to justify their position. Each justification is matched to stageindicative responses from the SRM-SF scoring manual. Questionnaires must yield seven scorable responses to be used for analysis. The primary score is the 
Sociomoral Reflection Mean Score (SRMS), the mean of the items, ranging from 100 to 400 . The measure is reported to have good reliability and validity (Gibbs et al., 1992).

Criminal sentiments. The Criminal Sentiments Scale (CSS) (Andrews \& Wormith, 1984) is a 41-item paper-and-pencil measure divided into three subscales. Subscale one measures Attitudes Toward the Law, Courts, and Police (ALCP). Subscale two measures Tolerance for Law Violation (TLV), and subscale three measures Identification With Criminal Others (ICO). Items are scored using a 5-point Likert-type scale, $1=$ strongly agree to $5=$ strongly disagree, and scaled in positive and negative directions. After reversal, lower ALCP scores reflect higher negativity toward the justice system and higher TLV and ICO scores reflect higher endorsement of neutralisations and identification with criminal peers. Good reliability and validity are reported (Andrews \& Wormith, 1984).

Criminal involvement. The Antisocial Behavior Scale (ABS) (Simourd, 1999) is a 24-item self-report measure of the frequency of criminal behaviour over a respondent's lifetime. Participants are asked how often they have engaged in a variety of criminal acts falling under five categories: driving offences, vandalism, drug related, theft/forgery, violence. Items are scored using a 4-point scale, $0=$ Never to $3=$ More than 4 times. Evaluation of the ABS using 155 Canadian federal offenders and 132 students found high discriminate validity, with offenders reporting having engaged in a wider range of acts (including more serious acts) and at a higher frequency than nonoffenders. Good reliability was also reported (Abbott, 2000). The ABS was used as a screening tool for the nonoffender group only.

\section{PROCEDURE}

Two procedures were used in this study. Although standardisation of data collection is advocated, this was not possible. Department of Justice guidelines required that prisoners taking part in research be seen individually and all measures to be completed in interview rooms during official visiting times. In contrast, due to the sensitive nature of the ABS, minimal contact between the researchers and student participants was deemed the most ethical procedure. Therefore, the students completed the measures in their own time.

Male offender participants were prisoners who were randomly selected from a 6-month intensive treatment program wait list for violent offending. At the time of this study, a female wait list had not been compiled. Female offender participants were selected at random from a name list identifying violent women offenders assessed as being at high risk. The offender participants were seen separately in official prison interview rooms. On arrival, participants were invited to volunteer for the study, which involved completing the SRM-SF and CSS. The time to complete the measures ranged from 40 to 90 minutes. 
Nonoffender participants were recruited through university lectures. A presentation describing the study was made and questionnaire packs distributed to volunteers. The order of questionnaires was the same as for the offender participants, the SRM-SF and CSS. In addition, nonoffenders completed the ABS to confirm their nonoffender status. The packs were completed and returned to a box anonymously.

\section{RESULTS}

To assess nonoffender status, the students' responses to the ABS were assessed by type of criminal involvement and frequency. Although the sample reported having engaged in some criminal behaviour, the acts were primarily traffic related (speeding), minor theft (shoplifting "once or twice"), and minor drug use (street drinking, cannabis use). No participant reported having engaged in violent behaviour (weapons offences, serious assaults, major theft) or reported a pattern suggesting chronic offending (wide range of offences and/or high frequency). Based on these findings, the students were classified as nonoffenders and were distinguishable from the offenders in this study, who all had known histories of serious violent and chronic criminal behaviour.

Thirty SRM-SF forms were scored blind by a second rater. Interrater agreement for the SRMS $(r(30)=.93, p<.001)$ was within the recommended range and consistent with prior research (Palmer \& Hollin, 1998).

Participants were categorised into four groups: level of sociomoral development (immature, Stages 1 to 2/3; and mature, Stages 3 to 4 ) and status (offender or nonoffender). As only seven nonoffenders had immature reasoning, they were excluded from the analysis. This left 193 participants in three groups (maturelevel nonoffenders ( $n=94)$, mature-level offenders $(n=64)$, and immature-level offenders $(n=35)$. The means and standard deviations by group and gender are presented in Table 1. As can be seen, the mature-level nonoffenders demonstrated higher mean sociomoral reasoning than mature-level offenders. Furthermore, the nonoffenders endorsed lower procriminal sentiments than mature-level offenders, who in turn endorsed lower procriminal sentiments than immature-level offenders.

\section{ENDORSEMENT OF CRIMINAL SENTIMENTS BY DEVELOPMENTAL LEVEL AND SEX}

A 3 (Group) $\times 2$ (Gender) MANOVA was used to see whether endorsement of criminal sentiments would differ by sociomoral level. The dependent variables (DVs) were ALCP, TLV, and ICO. The levels of group represented the classification of participants by developmental level and offender status as discussed above. On the combined DVs the effect of group, $F(6,372)=8.683, p<.001$, and 
TABLE 1

MEAN SOCIOMORAL REFLECTION MEASURE-SHORT FORM AND CRIMINAL SENTIMENTS SCALE SUBSCORES BY GROUP

\begin{tabular}{|c|c|c|c|c|c|c|c|c|c|}
\hline \multirow[b]{2}{*}{ Group } & \multirow[b]{2}{*}{$\mathrm{n}$} & \multicolumn{2}{|c|}{ SRMS } & \multicolumn{2}{|c|}{$A L C P$} & \multicolumn{2}{|c|}{$T L V$} & \multicolumn{2}{|c|}{ ICO } \\
\hline & & M & SD & M & SD & M & SD & M & SD \\
\hline \multicolumn{10}{|c|}{$\begin{array}{l}\text { Mature-level } \\
\text { nonoffenders }\end{array}$} \\
\hline Men & 45 & 340.22 & 22.83 & 85.24 & 11.49 & 26.02 & 4.82 & 15.16 & 2.63 \\
\hline Women & 49 & 339.18 & 19.62 & 87.47 & 12.90 & 25.22 & 4.78 & 13.92 & 3.03 \\
\hline \multicolumn{10}{|l|}{$\begin{array}{c}\text { Mature-level } \\
\text { offenders }\end{array}$} \\
\hline Men & 39 & 325.71 & 15.73 & 77.10 & 11.36 & 30.18 & 6.44 & 17.59 & 2.94 \\
\hline Women & 25 & 326.90 & 23.28 & 75.48 & 14.81 & 27.44 & 6.22 & 15.80 & 3.38 \\
\hline \multicolumn{10}{|c|}{$\begin{array}{l}\text { Immature-level } \\
\text { offenders }\end{array}$} \\
\hline Men & 19 & 274.70 & 19.11 & 75.32 & 17.14 & 31.42 & 6.85 & 18.37 & 4.37 \\
\hline Women & 16 & 271.31 & 19.83 & 68.81 & 11.67 & 31.44 & 6.82 & 18.25 & 3.11 \\
\hline
\end{tabular}

NOTE: SRMS = Sociomoral Reflection Mean Score; ALCP = Attitudes Towards the Law, Courts and Police; TLV = Tolerance for Law Violation; ICO = Identification With Criminal Others.

gender, $F(3,185)=3.300, p=.02$, were both significant, but the group by gender interaction was not significant, $F(6,372)=1.293, p=.26$. However, the effect size for group $\left(\eta^{2}=.123\right)$ and gender $\left(\eta^{2}=.051\right)$ were both small.

ANOVA on each of the DVs was performed as follow-up tests. To reduce the risk of Type I error, per test alpha was set at .0166. Significant differences were found for group on each DV, although the effect sizes were small; ALCP, $F(2$, $187)=20.232, p<.001 ; \eta^{2}=.178 ; \operatorname{TLV}, F(2,187)=14.605, p<.001 ; \eta^{2}=.135$ ICO, $F(2,187)=21.075, p .001 ; \eta^{2}=.184$. When the DVs were combined, the effect of gender had been significant, however, the univariate tests attributed the difference to only one variable, ICO, $F(1,187)=4.504, p=.04 ; \eta^{2}=.024$, with women identifying less than men. However, the probability value of .04 exceeded the alpha set for this analysis. For ALCP and TLV gender was insignificant, $F(1$, $187)=.932, p=.34 ;$ and $F(1,187)=1.683, p=.20$, respectively. The interaction of group by gender were all insignificant; ALCP, $F(2,187)=1.511, p=.22$; TLV, $F(2,187)=.796, p=.45 ;$ and $\mathrm{ICO}, F(2,187)=.788, p=.46$.

To identify which of the three groups differed from each other, Sheff tests were used. As expected, the nonoffenders differed significantly from the offender groups on all DVs with significance levels of $p<.002$ for all three comparisons. Contrary to expectation, the two offenders groups were not different from each other, $\operatorname{ALCP}(p=.32), \operatorname{TLV}(p=.16)$, and ICO $(p=.10)$. Although the Sheff tests showed that it was only the nonoffender group who were different, a pattern in the marginal means was apparent. The nonoffenders had more positive attitudes 
toward the justice system than mature-level offenders, followed by immaturelevel offenders $\left(M_{\text {nonoffenders }}=86.36 ; M_{\text {mature offenders }}=76.29 ; M_{\text {immature offenders }}=72.06\right)$. The nonoffenders were less willing to tolerate law violation than mature offenders, followed by immature offenders $\left(M_{\text {nonoffenders }}=25.62 ; M_{\text {mature offenders }}=28.81\right.$; $\left.M_{\text {immature offenders }}=31.43\right)$. The nonoffenders identified less with criminal others than mature offenders, followed by immature offenders $\left(M_{\text {nonoffenders }}=14.54\right.$; $M_{\text {mature offenders }}=16.70 ; M_{\text {immature offenders }}=18.31$ ).

The results of this study showed that regardless of an offenders level of moral reasoning, their endorsement of criminal sentiments clearly discriminated them from nonoffenders. Furthermore, although the marginal means showed that immature-level offenders endorsed higher criminal sentiments than mature-level offenders, the difference between the groups was not significant.

\section{DISCUSSION}

This study tested whether mature-level sociomoral development, rather than a buffer, could maintain affiliation to criminal others. Furthermore, that criminal behavior could be neutralized regardless of sociomoral level. However, due to differing worldviews provided by each developmental level, the following patterns in endorsement were predicted: Immature-level offenders would endorse higher procriminal sentiments than mature-level offenders, followed by mature-level nonoffenders.

The results supported this hypothesis, although not always significantly. As predicted, mature-level nonoffenders endorsed more positive attitudes about the justice system, were less willing to neutralize law violation, and had lower identification with criminal others than both offender groups. However, contrary to expectation, for the two offender groups, their level of sociomoral development did not affect their negative attitudes toward the justice system, their high tolerance for law violation, or high identification with criminal peers.

This result empirically demonstrates the enduring nature of criminal sentiments, where sociomoral development occurs while these sentiments remain embedded within the belief system. The following examples illustrate the finding that once criminal sentiments are internalised, sociomoral development simply accommodates them. These responses were made by participants convicted of armed robbery. Immature-level response (Stage 2): "Cause they have a job, me I' $m$ battling to get $\$ 5$ a week and I need to support my habit, they have insurance, can get their stuff back." Mature-level responses (Stage 3): "Don't we all steal, what are the governments doing if not stealing, but personal homes, no, its your conscience." (Stage 3.5): "When you rob banks, who is the worst criminal, the bank or the robber, how much social damage do banks do, does anyone question the banker's morals, but really this is only justifying it and you can't have people justifying everything or you'll have anarchy." These responses show that 
increased sociomoral development provided a less egocentric and pragmatic response, although the content remained clearly pro-offending.

In this study gender differences were not found, with men and women endorsing a similar level of criminal sentiments. Of note, the gender difference found for identification with criminal others was considered insignificant in this study due to the adjusted alpha level. However, if alpha was set at .05, men and women differed significantly in their endorsement, although the effect size was very weak, with gender only explaining $2.4 \%$ of the difference in identification. This finding is similar to the work of Alarid et al. (2000), where attachments to criminal peers, although significant for violent female offenders, was slightly stronger for males.

Cognitive developmental theory proposes that mature-level reasoning could act as a cognitive buffer against antisocial influences because mature reasoning provides an ability to understand and foresee the full consequences of your actions beyond the immediate situation. However, mature reasoning does not just provide the ability to understand the full consequences of your acts. Mature reasoning is also underpinned by wanting to maintain people's good opinion of you and where loyalty and honour underpin interpersonal relationships and affiliations. In other words, the obligations underpinning interpersonal relationships are especially important for mature reasoners. Bandura (1977) suggested that the importance mature reasoners place on ties to others could undermine adherence to prosocial norms given certain circumstances. The influence of criminal associates on others' offending behavior is contentious (refer to Andrew \& Bonta, 1998). However, research has found that the more attached you feel to criminal others, the more time you spend with them, and the more you want to behave in a way you believe they will condone, the more likely you are to engage in criminal behavior (Akers, 1985). This study has demonstrated that mature-level sociomoral development does not necessarily provide a cognitive buffer against antisocial influences and pro-offending sentiments.

Jennings et al. (1983) suggested that offending behavior was linked to the immature level of sociomoral development because people at this level use a pragmatic and egocentric approach to their consideration of whether norms should be upheld. In contrast, mature reasoners were suggested to have more consistent bonds to social norms because they understood the wider consequences of norms violation. This provides for an intuitive contradiction: How can a person who understands the consequences of their violent behavior still choose to engage in that behavior? We suggest it is at the mature level of reasoning that criminal sentiments have a powerful underlying psychological purpose. According to neutralisation theory, endorsement of criminal sentiments provided the psychological mechanism through which dissonance was reduced and self-concept maintained. This would explain why the $65 \%$ of high-risk adult violent offenders in this study with mature-level sociomoral development endorsed such a high level of procriminal sentiments, because without them a necessary self-protection mechanism is removed. However, having these sentiments within the belief system is one of the highest risk factors for reoffending because, as Akers (1985) stressed, 
these sentiments provide the motivation for choosing to engage in offending behavior, given the right circumstance. In other words, criminal sentiments maintain offending behavior.

One limitation of this study was that university students composed the comparison group. Shaughnessy and Zechmeister (1997) argued that because students are a selective subset of the population, any results obtained might not generalize to the wider community. In this study, the comparison group may have differed from the offender group on a number of variables not measured (such as socioeconomic status and education level). Future studies should consider using an ecologically valid nonoffender sample. This would address an important question: Would the observed interaction between criminal sentiments and levels of sociomoral development found in an offender sample differ from a sample of nonoffending men and women in the community?

Another limitation was that the differences between offenders and nonoffenders may be due to the two data collection methods employed. As the students completed the measures in their own time, this may have provided them with a longer time to consider their responses. The different method used is an important issue, especially as regards the SRM-SF, because the higher level of sociomoral reasoning demonstrated by the students may partly reflect time. We employed two procedures due to competing factors; on one hand to comply with Department of Justice guidelines concerning research using prisoners and on the other to assure students their responses would be anonymous. A replication of this study using the same data collection method for all participants could address this concern.

Of note, not uncommon for applied forensic research is the difficulty in confirming that nonoffenders are in fact nonoffenders. In this study we asked the student group to self-report the type and frequency of criminal behaviour they had engaged in. It is possible that some students underreported the frequency and/or severity of criminal acts. Therefore, it is possible that we have classified some participants who engage in a chronic level of criminal behaviour as nonoffenders. However, if the nonoffender sample was contaminated in this manner, the effect would be to weaken the observed significant differences between offenders and nonoffenders rather than to artificially inflate statistical findings.

This study found that mature-level sociomoral development might not necessarily protect a person from identifying with criminal others, and that law violation could be rationalized regardless of sociomoral stage. This has important applied implications. The rationale for sociomoral reasoning intervention was that a person could be competent in anger management, or communication skills, but may still choose to behave violently toward others because of a poor understanding of how personal actions affect others beyond the immediate situation (Jennings et al., 1983). The aim of intervention is to increase sociomoral reasoning to Stage 3 or above. As the majority of offenders in this sample (65\%) were at or above Stage 3, and because Stage 3 to 4 is considered the adult norm for the general population (Gibbs et al., 1992), an issue to consider is whether the major- 
ity of adult violent offenders require sociomoral intervention. Furthermore, the examples of reasoning concerning robbery, presented earlier, imply that regardless of developmental level, the content of the reasoning was criminogenic. This implies that practitioners working with high-risk violent adult offenders should devote intervention efforts to cognitive content (targeting pro-offending attitudes, beliefs, and identification with criminal peers) rather than cognitive structure (social perspective taking or moral development). Of note, the present findings are convergent with the large meta-analytical recidivism factors studies that suggest the highest risk factor for reoffending is pro-offending beliefs, and associations with criminal peers (Gendreau et al., 1996).

In summary, the present study found that for violent adult offenders, maturelevel sociomoral development might not necessarily buffer against antisocial influences. The results suggest that the offenders, regardless of their sociomoral developmental level, endorsed a more negative attitude toward the justice system, a high willingness to neutralise offending behaviour, and a high identification with criminal others. These findings provide an intuitive puzzle: How can a person engage in violent acts whilst understanding how their behavior can affect their victim beyond the immediate situation? It is possible that through the internalisation of criminal sentiments one psychological need can be met, a need that Aronson (1995) suggested most people can relate to: I am a reasonable person who does not hurt people without just cause. It is the just cause that criminal sentiments could provide. After all, if you consider your behaviour to be right given the circumstances, and with a belief that the people you identify with condone your behavior, then if other people condemn you, it must be the condemners who have it wrong. In sum, what you think could have a powerful influence on how you think.

\section{NOTE}

1. The Australian criminal justice system comprises the commonwealth jurisdiction and the state jurisdictions. Criminal law is mostly state based, with the commonwealth (or federal government) having very limited criminal jurisdiction (for example, social security fraud). Prison systems are state based, and there is only one system per state (there is no federal prison system). The limited number of offenders convicted of federal offences are held in state prisons. The offenders in this sample were drawn from maximum security prisons in the Western Australian prison system. There is no difference between the prisons that would have an impact on the selection of participants. Therefore, we sampled from the entire pool of violent offenders in Western Australia with no inherent sampling biases. Thus,

there is no reason to believe that the results from this study are not generalizable to high-risk violent offenders. 


\section{ACKNOWLEDGEMENTS}

The authors gratefully acknowledge the cooperation from staff and participants of the West Australian Department of Justice for allowing the opportunity to conduct this research. The opinions expressed in this article reflect those of the authors and do not necessarily reflect those of the Western Australian Department of Justice.

\section{REFERENCES}

Abbott, T. M. (2000). An investigation of the antisocial attitudes construct. Unpublished master's thesis, Carleton University, Ottawa, Canada.

Akers, R. L. (1985). Deviant behavior (3rd ed.). Belmont, CA: Wadsworth.

Alarid, L. F., Burton, V. S., \& Cullen, F. T. (2000). Sex and crime among felony offenders: Assessing the generality of social control and differential association. Journal of Research in Crime and Delinquency, 37, 171-199.

Andrews, D. A., \& Bonta, J. (1998). The psychology of criminal conduct (2nd ed.). Cincinnati, OH: Anderson.

Andrews, D. A., \& Wormith, J. S. (1984). The Criminal Sentiments Scale. Ottawa, Canada: Ministry of Correctional Services of Canada.

Aronson, E. A. (1995). The social animal (7th ed.). New York: Freeman.

Australian Institute of Criminology. (2001). Crime: Facts and figures 1999 [Brochure]. Canberra, Australia: Author.

Bandura, A. (1977). Social learning theory. Englewood Cliffs, NJ: Prentice Hall.

De Vries, B., \& Walker, L. J. (1986). Moral reasoning and attitudes toward capital punishment. Developmental Psychology, 22, 509-513.

Farrington, D. P. (1997). Human development and criminal careers. In M. Maguire, R. Morgan, \& R. Reiner (Eds.), The Oxford handbook of criminology (2nd ed., pp. 361-408). Oxford, UK: Clarendon.

Gendreau, P., Little, T., \& Goggin, C. (1996). A meta-analysis of the predictors of adult offender recidivism: What works. Criminology, 34, 575-595.

Gibbs, J. C., Basinger, K. S., \& Fuller, D. (1992). Moral maturity: Measuring the development of sociomoral reflection. Hillsdale, NJ: Lawrence Erlbaum.

Goldstein, A. P., Glick, B., \& Gibbs, J. C. (1998). Aggression replacement training (rev. ed.). Champaign, IL: Research Press.

Griffore, R. J., \& Samuels, D. D. (1978). Moral judgement of residents of a maximum security correctional facility. The Journal of Psychology, 100, 3-7.

Jennings, W. S., Kilkenny, R., \& Kohlberg, L. (1983). Moral-development theory and practice for youthful and adult offenders. In W. S. Laufer \& J. M. Day (Eds.), Personality theory, moral development, and criminal behavior (pp. 281-355). Toronto, Canada: Lexington.

Palmer, E. J., \& Hollin, C. R. (1998). A comparison of moral development in young offenders and nonoffenders. Legal and Criminological Psychology, 3, 225-235.

Shaughnessy, J. J., \& Zechmeister, E. B. (1997). Research methods in psychology (4th ed.). New York: McGraw-Hill.

Simourd, D. J. (1996). Criminal attitudes. In B. Wolfe (Ed.), Proceedings of the sixth symposium on violence. Saskatchewan, Canada: University of Saskatoon Extension Press.

Simourd, D. J. (1999). The Anti-Social Behaviour Scale. Ontario, Canada: Collins Bay Institute.

Stevenson, S., Hall, G., \& Innes, J. M. (in press). Sociomoral reasoning and criminal sentiments in Australian men and women violent offenders and non-offenders. International Journal of Forensic Psychology. 
Sykes, G. M., \& Matza, D. (1957). Techniques of neutralisation: A theory of delinquency. American Sociological Review, 22, 664-670.

Thornton, D., \& Reid, R. L. (1982). Moral reasoning and type of criminal offence. British Journal of Social Psychology, 21, 231-238.

Valliant, P. M., Gauthier, T., Pottier, D., \& Kosmyna, R. (2000). Moral reasoning, interpersonal skills, and cognition of rapists, child molesters, and incest offenders. Psychological Reports, 86, 67-75.

Walters, G. D. (1990). The criminal lifestyle: Patterns of serious criminal conduct. Newbury Park, CA: Sage.

Walters, G. D. (2002). The Psychological Inventory of Criminal Thinking Styles (PICTS): A review and meta-analysis. Assessment, 9, 278-291.

Ward, A., \& Dockerill, J. (1999). The predictive accuracy of the Violent Offender Treatment Program Risk Assessment Scale. Criminal Justice and Behavior, 26, 125-140.

Sally F. Stevenson, B.A. (Hons.), Bcom

Ph.D. Student

School of Psychology

Murdoch University

Perth

Western Australia, 6150

Guy Hall, Bpsy., Mpsych., Mbus

Senior Lecturer

School of Law

Murdoch University

Perth

Western Australia, 6150

J. M. Innes, M.A., Ph.D., FASSA, FAPS, FBPsS

Executive Dean, Humanities and Social Sciences

The University of Adelaide

South Australia, 5000 